\title{
PENGARUH KUALITAS PRODUK, HARGA DAN CITRA MEREK TERHADAP KEPUTUSAN PEMBELIAN SEPEDA MOTOR HONDA CBR150R DI CIBINONG
}

\author{
${ }^{1)}$ Dasmansyah Adyas, ${ }^{2)}$ Ifan Setiawan \\ ${ }^{1)}$ Dosen Program Studi Manajemen, STIE Dewantara \\ J1. Raya Pemda Bojong Depok Baru III, Karadenan, Cibinong, Bogor, Jawa Barat 16913, Indonesia \\ Email: dasmansyah.adyas@dewantara.ac.id \\ ${ }^{2)}$ Alumni Program Studi Manajemen, STIE Dewantara \\ Jl. Raya Pemda Bojong Depok Baru III, Karadenan, Cibinong, Bogor, Jawa Barat 16913, Indonesia \\ Email: ifansetiawan77@gmail.com
}

\begin{abstract}
This study aims to determine the effect of product quality, price and brand image on purchasing decisions of Honda CBR150R motorcycles in Cibinong. The number of samples used is 100 people using the formula Sugiyono (2013: 220). Test Results t product quality and price have a positive. Whereas the brand brand image partially does not have a effect on the purchase decision variable of the Honda CBR150R motorcycle in Cibinong. Test results of product quality, price and brand image simultaneously have a positive and significant effect on the variable purchase decision for Honda CBR150R motorcycles in Cibinong. The results of the analysis of determination correlation ( $R$ Square) amounted to 0.545 This means that purchasing decisions are influenced by product quality, price and brand image of $54.5 \%$ and the remaining $55.5 \%$ is influenced by other factors not included in this study.
\end{abstract}

Keywords: Product Quality, Price, Brand Image, Honda, Purchasing Decision.

\begin{abstract}
ABSTRAK
Penelitian ini bertujuan untuk mengetahui pengaruh kualitas produk, harga dan citra merek terhadap keputusan pembelian sepeda motor Honda CBR150R di Cibinong. Jumlah sampel yang digunakan sebanyak 100 orang dengan menggunakan rumus Sugiyono (2013:220). Hasil Uji t kualitas produk dan harga memiliki pengaruh yang positif. Sedangkan citra merek merek secara parsial tidak memiliki pengaruh terhadap variabel keputusan pembelian sepeda motor Honda CBR150R di Cibinong. Hasil uji kualitas produk, harga dan citra merek secara simultan ber-pengaruh secara positif dan signifikan terhadap variabel keputusan pembelian sepeda motor Honda CBR150R di Cibinong. Hasil analisis korelasi determinasi (R Square) sebesar 0,545 Hal ini berarti bahwa keputusan pembelian dipengaruhi oleh kualitas produk, harga dan citra merek sebesar $54,5 \%$ dan sisanya sebesar $55,5 \%$ dipengaruhi oleh faktor-faktor lain yang tidak dimasukkan dalam penelitian ini.
\end{abstract}

Kata kunci: Kualitaas Produk, Harga, Citra Merek (Brand Image), Honda, Keputusan Pembelian.

\section{PENDAHULUAN}

\subsection{Latar Belakang}

Pada saat ini perkembangan industri otomotif di Indonesia semakin kompetitif. Salah satunya adalah industri sepeda motor yang mana merupakan kendaraan beroda dua yang ditenagai oleh sebuah mesin, sekarang ini pengguna sepeda motor di Indonesia semakin meningkat. Banyak merek produk sepeda motor yang sudah dikenal oleh masyarakat diantaranya
Honda, Yamaha, Suzuki dan kawasaki. Namun salah satu merek yang paling digemari oleh masyarakat sejak dulu adalah merek Honda. Honda adalah merek sepeda motor di Indonesia yang dirakit dan didistribusikan oleh PT Astra Honda Motor.

Unggulnya produk Honda disertai dengan kemajuan teknologinya yang semakin canggih serta produk Honda yang semakin bervariasi, membuat produk ini semakin banyak di minati dan selalu unggul 
dari produk kendaraan bermotor merek lainnya. Honda mampu membidik hampir ke seluruh segmen pasar manapun, baik berdasarkan usia, jenis kelamin, sampai berdasarkan profesi para konsumen.

Industri sepeda motor di Indonesia memang memiliki cukup banyak pemain selain itu juga memiliki banyak tipe sepeda motor seperti kelas bebek, matic dan sport yang ditawarkan. Pada kelas motor sport 150CC Honda memiliki CBR150R. Pabrikan Honda telah banyak melakukan perubahan-perubahan yang sangat kompleks dengan menyesuaikan kemajuan teknologi yang ada pada sepeda motor CBR150R di kelas $150 \mathrm{CC}$ nya sehingga memilki banyak penggemar setia sampai sekarang ini. Namun di tahun 2018 semester I ini penjualan sepeda motor CBR150R mencenderung menurun di 3 bulan terakhir ini, yaitu pada bulan AprilJuni.

Berikut ini adalah data statistik penjualan sepeda motor CBR150R pada Semester I 2018 di Indonesia:

Tabel 1. Data Penjualan Sepeda Motor Honda CBR150R Semester 1 Tahun 2018 di Indonesia

\begin{tabular}{|c|c|}
\hline BULAN & CBR150R \\
\hline Januari & 4.642 unit \\
\hline Februari & 7.059 unit \\
\hline Maret & 6.268 unit \\
\hline April & 8.045 unit \\
\hline Mei & 7.210 unit \\
\hline Juni & 2.609 unit \\
\hline $\begin{array}{c}\text { Total } \\
\text { Penjualan }\end{array}$ & $\mathbf{3 5 . 8 2 4}$ Unit \\
\hline
\end{tabular}

Sumber : http://www.aisi.or.id (Di akses tanggal 25/11/2018 jam 14:00)

Dilihat dari data Tabel 1. Dari awal bulan Januari-Maret 2018 penjualan sepeda motor CBR150R mengalami pasang surut penjualan dan di bulan April-Juni mengalami penurunan yang sangat drastis.
Keputusan pembelian adalah salah satu pengaruh dari penjualan suatu produk akan naik ataupun turun. Sedangkan faktor yang da-pat mempengaruhi keputusan pembelian antara lain:

Faktor pertama yang mempengaruhi keputusan pembelian adalah kualitas produk. Kualitas produk saat ini sangat diperhatikan oleh konsumen. Konsumen menginginkan kualitas produk yang terbaik pada produk-produk yang telah dibeli.

Faktor kedua yang dapat mempengaruhi keputusan pembelian adalah harga. Dalam pengambilan keputusan harga merupakan salah satu pertimbangan penting, karena konsumen tentunya mengharapkan uang yang mereka keluarkan sesuai dengan apa yang mereka dapatkan.

Faktor ketiga yang dapat mempengaruhi keputusan pembelian adalah citra merek. Merek juga merupakan hal terpenting, karena merek akan membawa citra suatu perusahaan.

\subsection{Rumusan Masalah}

Dari latar belakang masalah, perumusan dalam penelitian ini adalah sebagai berikut:

1. Apakah kualitas produk, harga dan citra merek secara parsial berpengaruh terhadap keputusan pembelian produk sepeda motor Honda CBR150R pada masyarakat Cibinong?

2. Apakah kualitas produk, harga, dan citra merek secara simultan berpengaruh terhadap keputusan pembelian produk sepeda motor Honda CBR150R pada masyarakat Cibinong?

3. Faktor apakah diantara kualitas produk, promosi, dan citra merek yang mempunyai pengaruh paling dominan terhadap keputusan pembelian produk sepeda motor Honda CBR150R pada masyarakat Cibinong?

\subsection{Tujuan Penelitian}

Tujuan yang ingin dicapai dalam penelitian ini adalah sebagai berikut: 
1. Untuk mengetahui pengaruh kualitas produk, harga dan citra merek secara parsial terhadap keputusan pembelian produk sepeda motor Honda CBR150R pada masyarakat Cibinong.

2. Untuk mengetahui pengaruh kualitas produk, harga dan citra merek secara simultan terhadap keputusan pembelian produk sepeda motor Honda CBR150R pada masyarakat Cibinong.

3. Untuk mengetahui faktor yang mempunyai pengaruh paling dominan terhadap keputusan pembelian produk sepeda motor Honda CBR150R pada masyarakat Cibinong.

\section{TINJAUAN PUSTAKA}

\subsection{Pemasaran}

Menurut Kotler dan Armstrong (2008:6) pemasaran adalah proses dimana perusahaan menciptakan nilai bagi pelanggan dan membangun hubungan yang kuat dengan pelanggan dengan tujuan untuk menangkap nilai dari pelanggan sebagai imbalannya.

\subsection{Kualitas Produk}

Menurut Kotler dan Keller (2012:18), kualitas produk merupakan ciri dan karakteristik suatu barang atau jasa yang berpengaruh pada kemampuannya untuk memuaskan kebutuhan yang dinyata-kan atau tersirat.

\subsection{Harga}

Kotler dan Amstrong (2008: 73) mengatakan bahwa harga (price) adalah sejumlah uang yang harus dibayar oleh pelanggan untuk memperoleh produk.

\subsection{Citra Merek}

Menurut Kotler \& Keller (2009:378), citra merek adalah sekumpulan asosiasi merek yang terbentuk dan melekat di benak konsumen. Konsumen yang terbiasa menggunakan merek tertentu cenderung memiliki konsistensi terhadap merek.

\subsection{Keputusan Pembelian}

Menurut Kotler dan Armstrong (2008:227) mengemukakan bahwa keputusan pembelian adalah tahap proses keputusan dimana konsumen secara aktual melaku-kan pembelian produk. Menurut Kotler dan Armstrong (2008:224) proses pengambilan keputusan pembelian terdiri dari lima tahap yaitu pengenalan kebutuhan, pencarian informasi, pengevaluasian alternatif, keputusan pembelian, dan perilaku setelah pembelian.

\subsection{Definisi Operasional}

Berikut definisi operasional dijelaskan pada tabel 2 .

\section{Tabel 2. Definisi Operasional}

\begin{tabular}{|c|c|c|}
\hline Variabel & Indikator & Skala \\
\hline \multirow{7}{*}{$\begin{array}{l}\text { Kualitas } \\
\text { Produk } \\
\text { (X1) }\end{array}$} & $\begin{array}{l}\text { Kinerja (perfor- } \\
\text { mance) }\end{array}$ & \multirow{7}{*}{ Likert } \\
\hline & Fitur (features) & \\
\hline & $\begin{array}{l}\text { Keandalan (reli- } \\
\text { ability), }\end{array}$ & \\
\hline & $\begin{array}{l}\text { Kesesuaian de- } \\
\text { ngan spesifikasi } \\
\text { (conformance to } \\
\text { specifications) } \\
\end{array}$ & \\
\hline & $\begin{array}{l}\text { Daya tahan }(d u- \\
\text { rability })\end{array}$ & \\
\hline & Serviceability & \\
\hline & Estetika & \\
\hline \multirow{4}{*}{ Harga (X2) } & $\begin{array}{l}\text { Keterjangkauan } \\
\text { harga }\end{array}$ & \multirow{4}{*}{ Likert } \\
\hline & Daya saing har-ga & \\
\hline & $\begin{array}{l}\text { Kesesuaian har-ga } \\
\text { dengan kuali-tas } \\
\text { produk }\end{array}$ & \\
\hline & $\begin{array}{l}\text { Kesesuaian har-ga } \\
\text { dengan man-faat } \\
\text { produk }\end{array}$ & \\
\hline \multirow{3}{*}{$\begin{array}{l}\text { Citra merek } \\
\text { (X3) }\end{array}$} & $\begin{array}{l}\text { Kekuatan Merek } \\
\text { (Strengthness) }\end{array}$ & \multirow{3}{*}{ Likert } \\
\hline & $\begin{array}{l}\begin{array}{l}\text { Keunikan Merek } \\
\text { (Uniqueness) }\end{array} \\
\end{array}$ & \\
\hline & $\begin{array}{l}\text { Keunggulan Merek } \\
\text { (Favo-rable) }\end{array}$ & \\
\hline $\begin{array}{l}\text { Keputus } \\
\text { an pem- }\end{array}$ & $\begin{array}{l}\text { Pengenalan ke- } \\
\text { butuhan. }\end{array}$ & Likert \\
\hline
\end{tabular}




\begin{tabular}{|l|l|}
\hline belian (Y) & $\begin{array}{l}\text { Pencarian infor- } \\
\text { masi. }\end{array}$ \\
\cline { 2 - 2 } & Evaluasi alterna-tif \\
\cline { 2 - 2 } & $\begin{array}{l}\text { Menentukan } \\
\text { pembelian }\end{array}$ \\
\cline { 2 - 2 } & $\begin{array}{l}\text { Perilaku setelah } \\
\text { pembelian }\end{array}$ \\
\hline
\end{tabular}

\subsection{Kerangka Pemikiran}

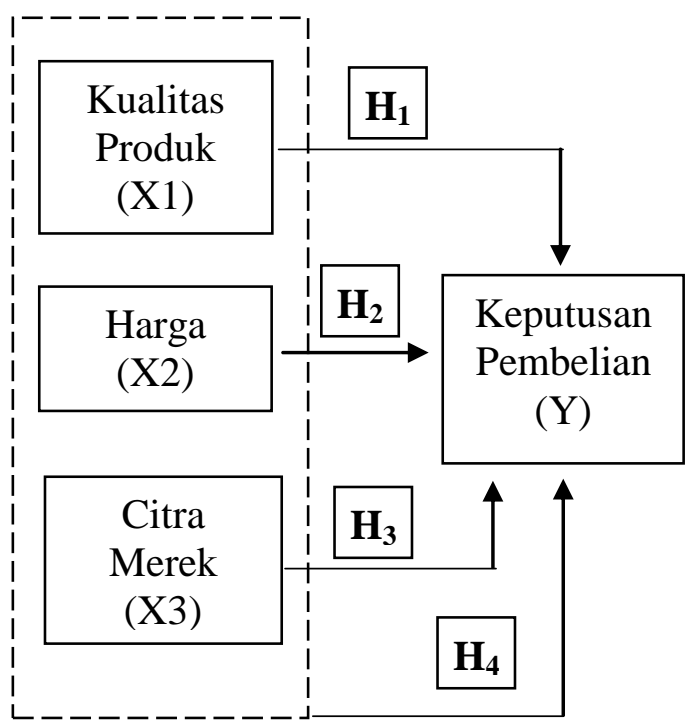

Gambar 1. Kerangka Pemikiran

\section{METODE PENELITIAN}

\subsection{Jenis Penelitian}

Penelitian ini merupakan jenis penelitian kuantitatif. Penelitian ini termasuk jenis penelitian kuantitatif kausalitas.

\subsection{Variabel Penelitian}

Variabel yang digunakan dalam penelitian ini adalah variabel independen yaitu Kualitas Produk (X1), Harga (X2), dan Citra Merek (X3). Sedangkan variabel dependen dalam penelitian ini adalah Keputusan Pembelian (Y).

\subsection{Waktu dan Lokasi Penelitian}

Waktu penelitian dilaksanakan pada bulan oktober - desember 2018. Lokasi penelitian di lokasi Stadion Pakansari Cibinong, CV Chikara, Dua Cakrawala, Karunia Motor, Rastra Motor, PT Murni Motor.

\subsection{Objek Penelitian}

Objek penelitiannya adalah pemilik sepeda motor Honda CBR150R yang menggunakan lebih dari 1 bulan.

\subsection{Populasi dan Sampel \\ 3.5.1 Populasi}

Menurut Sugiyono

(2014:115), populasi adalah wilayah generalisasi yang terdiri atas objek atau subjek yang mempunyai kuantitas dan karakteristik tertentu yang ditetapkan oleh peneliti untuk diperlajari dan kemudian ditarik kesimpulannya. Populasi dalam penelitian ini adalah pemilik sepeda motor Honda CBR150R di Cibinong.

\subsubsection{Sampel}

Sampel adalah bagian dari populasi yang diambil melalui cara-cara tertentu, yang juga memiliki karakteristik tertentu, jelas dan lengkap yang dianggap bisa mewakili populasi. Bila populasi besar, dan peneliti tidak mungkin meneliti semua yang ada pada populasi, misalnya karena keterbatasan dana, tenaga, waktu, maka peneliti dapat menggunakan sampel yang diambil dari populasi itu. Sugiyono (2014:116).

Sampel dalam penelitian ini adalah pemilik sepeda motor Honda CBR150R yang menggunakan sepeda motor di Cibinong dengan lama penggunaan lebih dari satu bulan.

\subsection{Teknik Pengambilan Sampel}

Teknik pengambilan sample dalam penelitian ini menggunakaan teknik Accidental sampling. Dalam penelitian bisa saja terjadi diperolehnya sampel yang tidak direncanakan terlebih dahulu, melainkan secara kebetulan, yaitu unit atau subjek tersedia bagi peneliti saat pengumpulan data dilakukan. Tek-nik pengambilan sampel menggunakan metode Accidental Quota Sampling yaitu teknik pengambilan sampel yang dapat dilakukan sewaktuwaktu sam-pai jumlah sampel (quota) yang diinginkan terpenuhi Kuntjojo (2009:33). 
Teknik pengumpulan dilakukan dengan cara dokumentasi dan kuesioner. Ukuran populasi dalam penelitian ini sangat banyak dan beragam sehingga tidak dapat di ketahui dengan pasti, maka rumus yang digunakan untuk menghitung besaran sampel adalah sebagai berikut (Sugiyono, 2013: 220)

$$
\begin{aligned}
& n=\frac{Z^{2}}{4 M 0 e^{2}} \\
& n=\frac{1,960^{2}}{4 \times 10 \%^{2}} \\
& n=\frac{3,8416}{0,04} \\
& n=96.04 \text { atau dibulatkan menjadi } \\
& 100
\end{aligned}
$$

Keterangan :

$\mathrm{n}=$ Ukuran sampel

$\mathrm{Z}=1,960$ score pada tingkat signifikansi tertentu

Moe $=$ Margin of Eror (tingkat kesalahan maksimum $10 \%$ )

Berdasarkan hasil perhitungan maka akan di teliti sebanyak 100 sampel dalam penelitian ini.

\subsection{Teknik Analisis Data}

Teknik analisis data dalam penelitian ini menggunakan uji validitas, uji reliabilitas, uji asumsi klasik, regresi linear berganda dan uji koefisien determinasi.

\section{HASIL DAN PEMBAHASAN}

\subsection{Uji Validitas}

Uji validitas digunakan untuk mengukur sah atau valid tidaknya suatu kuesioner. Dalam penentuan layak atau tidaknya suatu item yang digunakan, dilakukan uji sig-nifikansi koefisien korelasi pada taraf signifikansi 0,1 . Suatu data dikatakan valid apabila $r$ hitung $\geq r$ tabel.
Nilai $r$ tabel jumlah responden sebanyak 100 responden dengan ta-raf signifikansi 0,1 dan $\mathrm{df}=100$ sehingga memperoleh nilai sebesar 0,1638 . Berdasarkan hasil pengujian uji validitas kualitas produk, harga , citra merek dan Keputusan Pem-belian (Y) semua item pertanyaan kuesioner dinyatakan valid.

\section{Tabel 3. Hasil Uji Validitas Variabel} Kualitas Produk

\begin{tabular}{|c|c|c|c|c|}
\hline $\begin{array}{c}\text { Varia } \\
\text { bel }\end{array}$ & $\begin{array}{c}\text { Butir } \\
\text { Perta } \\
\text { yaan }\end{array}$ & $\begin{array}{c}\mathrm{R} \\
\text { Hitung }\end{array}$ & $\begin{array}{c}\mathrm{R} \\
\text { Tabel }\end{array}$ & Ket \\
\hline \multirow{3}{*}{$\begin{array}{c}\text { Kuali } \\
\text { tas } \\
\text { Produ } \\
\text { k }\end{array}$} & $\mathrm{X} 1.1$ & 0,766 & 0,1638 & Valid \\
\cline { 2 - 5 } & $\mathrm{X} 1.2$ & 0,586 & 0,1638 & Valid \\
\cline { 2 - 5 } X1) & $\mathrm{X} 1.3$ & 0,675 & 0,1638 & Valid \\
\cline { 2 - 5 } & $\mathrm{X} 1.4$ & 0,775 & 0,1638 & Valid \\
\cline { 2 - 5 } & $\mathrm{X} 1.6$ & 0,703 & 0,1638 & Valid \\
\cline { 2 - 5 } & $\mathrm{X} 1.7$ & 0,564 & 0,1638 & Valid \\
\hline
\end{tabular}

Sumber: Data Primer (kuesioner), diolah (2018)

Tabel 4. Hasil Uji Validitas Variabel Harga

\begin{tabular}{|c|c|c|c|c|}
\hline $\begin{array}{c}\text { Varia } \\
\text { bel }\end{array}$ & $\begin{array}{c}\text { Butir } \\
\text { Perta } \\
\text { yaan }\end{array}$ & $\begin{array}{c}\mathrm{R} \\
\text { Hitung }\end{array}$ & $\begin{array}{c}\mathrm{R} \\
\text { Tabel }\end{array}$ & Ket \\
\hline Harg & $\mathrm{X} 2.1$ & 0,839 & 0,1638 & Valid \\
\cline { 2 - 5 } & $\mathrm{X} 2.2$ & 0,702 & 0,1638 & Valid \\
\cline { 2 - 5 }$(\mathrm{X} 2)$ & $\mathrm{X} 2.3$ & 0,780 & 0,1638 & Valid \\
\cline { 2 - 5 } & $\mathrm{X} 2.4$ & 0,791 & 0,1638 & Valid \\
\hline
\end{tabular}

Sumber: Data Primer (kuesioner), diolah (2018)

Tabel 5. Hasil Uji Validitas Variabel Citra Merek

\begin{tabular}{|c|c|c|c|c|}
\hline $\begin{array}{c}\text { Varia } \\
\text { bel }\end{array}$ & $\begin{array}{c}\text { Butir } \\
\text { Perta } \\
\text { yaan }\end{array}$ & $\begin{array}{c}\mathrm{R} \\
\text { Hitung }\end{array}$ & $\begin{array}{c}\mathrm{R} \\
\text { Tabel }\end{array}$ & Ket \\
\hline $\begin{array}{c}\text { Citra } \\
\text { Mere } \\
\mathrm{k}\end{array}$ & $\mathrm{X} 3.1$ & 0,725 & 0,1638 & Valid \\
\cline { 2 - 5 }$(\mathrm{X} 3.2$ & 0,836 & 0,1638 & Valid \\
\hline X3 $)$ & & 0,786 & 0,1638 & Valid \\
\hline
\end{tabular}

Sumber: Data Primer (kuesioner), diolah (2018) 
Tabel 6. Hasil Uji Validitas Variabel Keputusan Pembelian

\begin{tabular}{|c|c|c|c|c|}
\hline $\begin{array}{c}\text { Varia } \\
\text { bel }\end{array}$ & $\begin{array}{l}\text { Butir } \\
\text { Perta } \\
\text { yaan }\end{array}$ & $\begin{array}{c}\mathrm{R} \\
\text { Hitung }\end{array}$ & $\begin{array}{c}\mathrm{R} \\
\text { Tabel }\end{array}$ & Ket \\
\hline \multirow{5}{*}{$\begin{array}{l}\text { Kepu } \\
\text { tusan } \\
\text { Pem } \\
\text { belia } \\
n(Y)\end{array}$} & Y.1 & 0,809 & 0,1638 & Valid \\
\hline & Y.2 & 0,882 & 0,1638 & Valid \\
\hline & Y.3 & 0,844 & 0,1638 & Valid \\
\hline & Y.4 & 0,782 & 0,1638 & Valid \\
\hline & Y.5 & 0,614 & 0,1638 & Valid \\
\hline
\end{tabular}

Sumber: Data Primer (kuesioner), diolah (2018)

\subsection{Hasil Uji Reliabilitas}

Pengujian reliabilitas dilakukan sebagai salah satu pengukuran yang menunjukkan konsistensi dan stabilitas dari suatu skor (skala peng-ukuran). Pengujian reliabilitas dilakukan dengan menggunakan program SPSS V.23. Dalam pengukuran realiabilitas, kuesioner dinyatakan reliabel apabila nilai Cronbach's Alpha lebih besar atau sama dengan 0,60. Hasil pengujian reliabilitas dapat dilihat dalam tabel dibawah ini :

Tabel 7. Hasil Uji Reliabilitas Variabel Kulitas Produk

Reliability Statistics

\begin{tabular}{|r|r|}
\hline $\begin{array}{c}\text { Cronbach's } \\
\text { Alpha }\end{array}$ & N of Items \\
\hline, 765 & 8 \\
\hline
\end{tabular}

Sumber: Data Primer (kuesioner),diolah (2018)

Berdasarkan tabel 7 dapat disimpulkan bahwa instrumen variabel Kualitas Produk ini dikatakan reliabel, dikarenakan Cronbach's Alpha sebesar 0,765 dalam kategori lebih besar dari 0,60 dianggap sebagai reliabel atau baik.
Tabel 8. Hasil Uji Reabilitas Variabel Harga

\section{Reliability Statistics}

\begin{tabular}{|r|r|}
\hline $\begin{array}{c}\text { Cronbach's } \\
\text { Alpha }\end{array}$ & N of Items \\
\hline, 807 & 5 \\
\hline
\end{tabular}

Sumber: Data Primer (kuesioner), diolah (2018)

Berdasarkan tabel 8 dapat disimpulkan bahwa instrumen variabel harga ini dikatakan reliabel, dikarenakan Cronbach's Alpha sebesar 0,807 dalam kategori lebih besar dari 0,60 dianggap sebagai reliabel atau baik.

Tabel 9. Hasil Uji Reabilitas Variabel Citra Merek

Reliability Statistics

\begin{tabular}{|r|r|}
\hline $\begin{array}{c}\text { Cronbach's } \\
\text { Alpha }\end{array}$ & N of Items \\
\hline, 818 & 4 \\
\hline
\end{tabular}

Sumber: Data Primer (kuesioner), diolah (2018)

Berdasarkan tabel 9 dapat disimpulkan bahwa instrumen variabel citra merek ini dikatakan reliabel, dikarenakan Cronbach's Alpha sebesar 0,818 dalam kategori lebih besar dari 0,60 dianggap sebagai reliabel atau baik.

Tabel 10. Hasil Uji Reabilitas Variabel Keputusan Pembelian

Reliability Statistics

\begin{tabular}{|r|r|}
\hline $\begin{array}{c}\text { Cronbach's } \\
\text { Alpha }\end{array}$ & N of Items \\
\hline, 803 & 6 \\
\hline
\end{tabular}

Sumber: Data Primer (kuesioner), diolah (2018)

Berdasarkan tabel 10 dapat disimpulkan bahwa instrumen variabel keputusan pembelian ini dikatakan reliabel, dikarenakan Cronbach's Alpha sebesar 
0,803 dalam kategori lebih besar dari 0,60 dianggap sebagai reliabel atau baik.

\subsection{Uji Asumsi Klasik}

\subsubsection{Uji Normalitas}

Uji normalitas menggunakan uji Kolmogorov-Smirnov, dengan uji ini dapat diketahui data yang digunakan berdistribusi normal atau tidak. Apabila nilai signifikansi $>0.1$, maka data tersebut berdistribusi normal dan begitu juga sebaliknya. Hasil pengujian Normalitas dapat dilihat di tabel di bawah ini :

Tabel 11. Hasil Uji Normalitas

One-Sample Kolmogorov-Smirnov Test

\begin{tabular}{|ll|r|}
\hline & & $\begin{array}{r}\text { Unstandardized } \\
\text { Residual }\end{array}$ \\
\hline $\mathrm{N}$ & & 100 \\
Normal & Mean &, 0000000 \\
Parameters & Std. & 2,66199458 \\
$\mathrm{a}, \mathrm{b}$ & Deviation &, 065 \\
Most & Absolute &, 064 \\
Extreme & Positive &,- 065 \\
Difference & Negative &, 065 \\
s & &, $200^{\mathrm{c}, \mathrm{d}}$ \\
Test Statistic & \\
Asymp. Sig. (2-tailed) &
\end{tabular}

a. Test distribution is Normal.

b. Calculated from data.

c. Lilliefors Significance Correction.

Sumber: Data Primer (kuesioner), diolah (2018)

Berdasarkan tabel 11 dapat disimpulkan bahwa data yang digunakan berdistribusi normal, di-karenakan nilai signifikansi sebesar 0,20 dalam kategori lebih besar dari 0,1 dianggap berdistribusi normal.

\subsubsection{Uji Multikolinieritas}

Uji multikolinieritas digunakan untuk mengetahui apakah antara variabel bebas terjadi multikolinieritas atau tidak. Uji yang digunakan dengan teknik korelasi product mo-ment. Interpretasinya adalah jika har-ga interkorelasi antar variabel bebas lebih dari atau sama dengan 0,800 berarti antar variabel tersebut terjadi multikolinieritas, demikian juga sebaliknya atau dengan melihat nilai VIF (Varian Inflation Factor) dan toleransi pada proses nregresi biasa, jika kedua mendekati 1 atau besaran VIF kurang dari 10 maka model tidak terkena multikolinearitas dapat dilihat di tabel di bawah ini :

Tabel 12. Hasil Uji Multikolinearitas

\begin{tabular}{|c|c|c|}
\hline Variabel & Toleransi & VIF \\
\hline $\mathrm{X} 1$ & 0,576 & 1,735 \\
\hline $\mathrm{X} 2$ & 0,661 & 1,512 \\
\hline $\mathrm{X} 3$ & 0,658 & 1,519 \\
\hline
\end{tabular}

Sumber : Data Primer (kuesioner), diolah (2018)

Berdasarkan tabel 12 dapat disimpulkan bahwa interkorelasi antar variabel bebas tidak ada nilai yang lebih dari atau sama dengan 0,800 dan atau besaran VIF kurang dari 10 maka disimpulkan tidak terjadi multikolonieritas.

\subsubsection{Uji Heterokedastisitas}

Uji Heteroskedastisitas bertujuan menguji apakah dalam model regresi terjadi ketidaksamaan vari-ance dari residual satu pengamatan ke pengamatan lain.

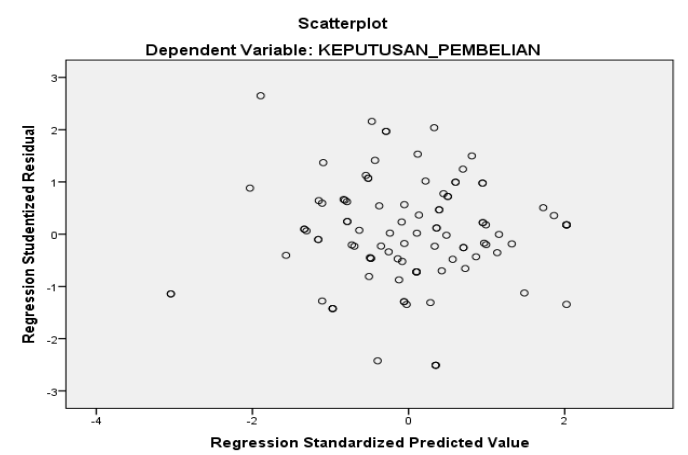

Gambar 2. Hasil Uji Heteroskedasitisitas

Berdasarkan gambar 2 dapat disimpulkan bahwa titik-titik menyebar secara acak, serta tersebar baik di atas maupun dibawah angka nol pada sumbu Y. 
Hal ini dapat disimpulkan bahwa tidak terjadi heteroskedastisitas pada model regresi.

\subsection{Analisis Regresi Linier Berganda}

Analisis Regresi Linier Berganda bertujuan untuk mengetahui pengaruh kualitas produk, harga, dan citra merek terhadap keputusan pembelian. Hasil pengujian uji regresi linier berganda di peroleh nilai koefisien konstan sebesar 0,288 , koefisien kualitas produk (X1) sebesar 0,468, koefisien harga (X2) sebesar 0,400 , koefisien citra merek (X3) sebesar 0,10 . Berdasarkan hasil tersebut, persamaan regresi dapat dirumuskan sebagai berikut:

Tabel 13. Hasil Uji Analisis Regresi Linier Berganda

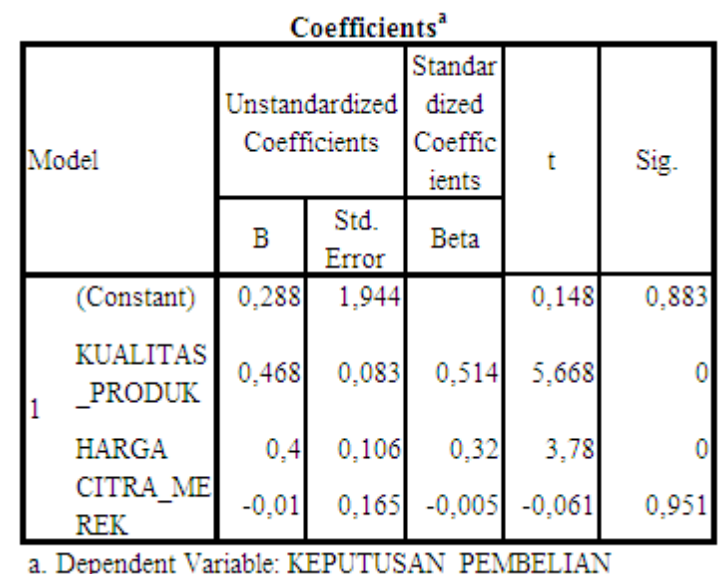

$$
\begin{aligned}
& Y=a+b_{1} X_{1}+b_{2} X_{2}+b_{3} X_{3} \\
& Y=0,288+0,468 X 1+0,400 X 2+ \\
& (-0,10 X 3)
\end{aligned}
$$

Dimana :

$\mathrm{Y}=$ Keputusan pembelian

$\mathrm{X} 1=$ Kualitas produk

$\mathrm{X} 2$ = Harga

X3 = Citra Merek

$\mathrm{a}=0,288$

Interpretasi hasil dari model regresi persamaan linier berganda yaitu:
1. Berarti bahwa nilai konstanta (a) kualitas produk, harga, citra merek dianggap konstan terhadap keputusan pembeliannya, maka keputusan pembelian sebesar 0,288.

2. $\mathrm{b}_{1}=$ Koefisien regresi kualitas produk sebesar 0,468 menyatakan bahwa apabila kualitas produk meningkat sebesar satu satuan, maka keputusan pembelian akan meningkat sebesar 0,468 satuan.

3. $\mathrm{b}_{2}=$ Koefisien regresi harga sebesar 0,400 menyatakan bahwa apabila harga meningkat sebesar satu satuan, maka keputusan pembelian akan meningkat sebe-sar 0,400 satuan.

4. $b_{3}=$ Koefisien regresi citra merek sebesar -0,10 menyatakan bahwa apabila citra merek meningkat se-besar satu satuan, maka keputusan pembelian akan menurun sebesar 0,10 satuan.

Berdasarkan hasil analisis linear berganda menunjukkan variabel produk dan harga memiliki pengaruh positif terhadap keputusan pembelian. Sementara variabel citra merek memiliki pengaruh negatif terhadap keputusan pembelian.

\subsection{Uji T}

Uji ini digunakan untuk me-ngetahui apakah masing-masing variabel bebas secara individual berpengaruh signifikan terhadap variabel terikat. Pengujian dilakukan dengan membandingkan an-tara nilai $\mathrm{t}$ hitung masing-masing variabel bebas dengan nilai $\mathrm{t}$ tabel dengan peluang kesalahan $10 \%(\mathrm{a}=0,1)$. 
Tabel 14. Hasil Uji T

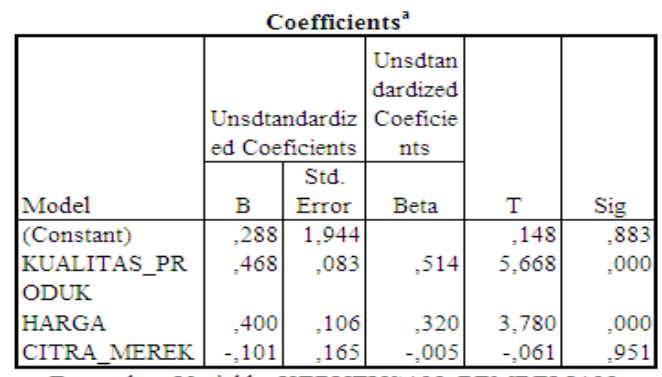

a. Dependent Variable: KEPUTUSAN_PEMBELIAN

Sumber: Data Primer (kuesioner), diolah (2018).

Dari tabel 14 diatas menunjukkan bahwa $t$ hitung $(5,668)>t$ tabel $(1,661)$ dengan taraf signifikansi $0,000<0,1$. Maka Ho ditolak dan hipotesis yang diterima adalah $\mathrm{H}_{1}$ yang berarti variabel kualitas produk secara parsial memiliki pengaruh yang positif dan signifikan terhadap variabel keputusan pembelian sepeda motor Honda CBR150R di Cibinong.

Bahwa t hitung $(3,780)>\mathrm{t}$ tabel $(1,661)$ dengan taraf signifikansi $0,000<$ 0,1. Maka Ho ditolak dan hipotesis yang diterima adalah $\mathrm{H}_{1}$ yang berarti variabel harga secara parsial memiliki pengaruh yang positif dan signifikan terhadap variabel keputusan pembelian sepeda motor Honda CBR150R di Cibinong.

Bahwa $\mathrm{t}$ hitung $(-0,61)<\mathrm{t}$ tabel $(1,661)$ dengan taraf signifikansi $0,951>$ 0,1 . Maka $\mathrm{H}_{1}$ ditolak dan hipotesis yang diterima adalah Ho yang berarti variabel citra merek secara parsial tidak memiliki pengaruh yang positif dan signifikan terhadap variabel keputusan pembelian sepeda motor Honda CBR150R di Cibinong. Variabel bebas yang memiliki pengaruh paling besar terhadap keputusan pembelian adalah variabel kualitas produk dengan $\mathrm{t}$ hitung $(3,780)>\mathrm{t}$ tabel $(1,661)$ dengan taraf signifikansi $0,000<0,1$.

\subsection{Uji F}

Uji $F$ bertujuan untuk mengetahui pengaruh secara simultan variabel independen terhadap variabel dependen.
Tabel 15. Hasil Uji F

\begin{tabular}{|c|c|c|c|c|c|}
\hline \multicolumn{6}{|c|}{ ANOVA $^{\mathrm{a}}$} \\
\hline Model & $\begin{array}{l}\text { Sum of } \\
\text { Squares }\end{array}$ & Df & $\begin{array}{l}\text { Mean } \\
\text { Square }\end{array}$ & $f$ & Sig \\
\hline Regression & 839,505 & 3 & 279,835 & 38,293 & $000^{\circ}$ \\
\hline Residual & 701,535 & 96 & 7,308 & & \\
\hline Total & 1541,040 & 99 & & & \\
\hline
\end{tabular}

Sumber: Data Primer (kuesioner), diolah (2018)

Hasil Uji F diketahui F hitung $(38,293)$ $>$ Ftabel $(2,14)$ dengan taraf signifikansi (sig) $0,000<0,1$. Maka variabel kualitas produk, harga dan citra merek secara simultan berpengaruh secara positif dan signifikan terhadap variabel keputusan pembelian sepeda motor Honda CBR150R di Cibinong.

\subsection{Uji Koefisien Determinasi $\left(\mathbf{R}^{2}\right)$}

Koefisien Determinasi $\left(\mathrm{R}^{2}\right)$ bertujuan mengukur seberapa jauh kemampuan model dalam menerangkan variasi variabel terikat.

Dalam penelitian ini perhitungan koefisien determinasi untuk mengukur seberapa jauh kemampuan variabelvariabel bebas (kua-litas produk, harga, dan citra me-rek) dalam menjelaskan variabel terikat (keputusan pembelian).

Tabel 16. Hasil Uji Koefisien Determinasi

\begin{tabular}{|c|c|c|c|c|}
\hline \multicolumn{5}{|c|}{ Model Summary } \\
\hline $\begin{array}{l}\text { Mo } \\
\text { del }\end{array}$ & $\mathrm{R}$ & $\begin{array}{c}\mathrm{R} \\
\text { Square }\end{array}$ & $\begin{array}{l}\text { Adjusted R } \\
\text { Square }\end{array}$ & $\begin{array}{l}\text { Std. Error } \\
\text { of the } \\
\text { Estimate }\end{array}$ \\
\hline 1 &, 738 & ,545 &, 531 & 2,703 \\
\hline
\end{tabular}

a. Predictors: (Constant), Citra_merek, Harga, Kualitas_Produk

Sumber : Data Primer (kuesioner), diolah (2018).

Berdasarkan tabel 16 dari hasil koefisien determinasi dapat diketahui bahwa nilai $\mathrm{R}=0,738$. Untuk mengetahui 
besarnya variasi dari keputusan pembelian dapat dilihat dari nilai Adjusted R Square yang diperoleh sebesar 0,545. Hal ini berarti bahwa variasi dari keputusan pembelian dipengaruhi oleh kualitas produk, harga dan citra merek se-besar $54,5 \%$ dan sisanya sebesar 55,5\% dipengaruhi oleh faktor-faktor lain yang tidak dimasukkan dalam penelitian ini.

\section{Kesimpulan dan Saran}

\subsection{Kesimpulan}

Berdasarkan hasil analisis yang telah dilakukan maka dapat ditarik beberapa kesimpulan sebagai berikut :

1. Kualitas produk dan harga secara parsial memiliki pengaruh yang positif dan signifikan terhadap variabel keputusan pembelian sepeda motor Honda CBR150R di Cibinong dengan nilai $\mathrm{t}$ hitung $(5,668)>\mathrm{t}$ tabel $(1,661)$ dengan taraf signifikansi $0,000<0,1$ untuk kualitas produk dan nilai t hitung $(3,780)>\mathrm{t}$ tabel $(1,661)$ dengan taraf signifikansi $0,000<0,1$ untuk harga. Sedangkan citra merek secara parsial tidak memiliki pengaruh yang signifikan terhadap variabel keputusan pembelian dengan nilai t hitung $(-0,61)$ $<\mathrm{t}$ tabel $(1,661)$ dengan taraf signifikansi $0,951>0,1$. Artinya bagi pemilik CBR150R citra merek tidak berpengaruh karena mereka lebih mengutamakan kualitas dan harga.

2. Variabel kualitas produk, harga dan citra merek secara simultan berpengaruh secara positif dan signifikan terhadap variabel keputusan pembelian sepeda motor Honda CBR150R di Cibinong.

3. Variabel bebas yang memiliki pengaruh paling besar terhadap keputusan pembelian adalah variabel kualitas produk.

\subsection{Saran}

Berdasarkan hasil kesimpulan di atas, ada beberapa saran yang dapat dikemukakan peneliti bagi pihak yang terkait dengan penelitian ini dan juga penelitian selanjutnya. Saran tersebut antara lain sebagai berikut:

1. Disarankan bagi pihak produsen perlu keinginan konsumen terutama dalam kualitas yang memiliki pengaruh paling besar agar dapat mempengaruhi keputusan pembelian dan untuk mengembangkan perusahaan, memperluas pangsa pasarnya serta meningkatkan penjualan produknya.

2. Disarankan bagi peneliti selanjutnya dapat mengembangkan penelitian ini dengan meneliti faktor lain yang dapat mempengaruhi keputusan pembelian. Saran yang dapat peneliti berikan adalah peneliti selanjutnya dapat mencoba variabel lain seperti promosi, dan gaya hidup. Sehingga diperoleh informasi yang lebih bervariasi tentang variabel-variabel yang berpengaruh terhadap keputusan pembelian sepeda motor Honda CBR150R.

\section{DAFTAR PUSTAKA}

Daryanto. 2011. Sari Kuliah Manajemen Pemasaran Cetakan Pertama. Bandung: PT. Sarana Tutorial Nurani Sejahtera.

Ghozali, Imam. 2011. Aplikasi Analisis Multivariate dengan Program SPSS. Universitas Diponegoro Semarang.

Harjuno, Purgo. 2018. "Pengaruh Kualitas Produk, Persepsi Harga, Dan Citra Merek Terhadap keputusan Pembelian Motor Matic Honda Scoopy (Studi Kasus Pada Mahasiswa Universitas Negeri Yogyakarta)". Universitas Negeri Yogyakarta. Yogyakarta.

Kotler, Philip. Armstrong, Gary. 2008. Prinsip-Prinsip Pema- saran Edisi 12. Jilid 1 Terjemahan Bob Sabran. Jakarta : Erlangga.

Kotler, Philip. Keller, Kevin Lane. 2009. Manajemen Pemasaran Edisi 13 
Jilid 1. Terjemahan $B o b$

Sabran. Jakarta : Erlang- ga.

Kotler, Philip. 2012. Manajemen Pemasaran. Edisi 11 Jilid 2 Edisi Bahasa Indonesia. Jakarta: Indeks.

Kuntjojo. 2009. Metode Penelitian. Universitas Nusantara PGRI. Kediri.

Noor, Juliansyah. 2011. Metode Penelitian Skripsi Tesis, Disertasi, Dan Karya Ilmiah. Jakarta : Pranamedia Group.

Sangadji, Etta Mamang. Sopiah. 2013. Perilaku Konsumen Pendekatan Praktis Disertai Himpunan Jurnal Penelitian Edisi 1. Yogyakarta : Andi Offset.

Senly Alvian, 2017. "Pengaruh citra merek (brand image) terhadap pengambilan keputusan pembelian mobil Mitsubishi Colt Diesel pada PT Bosowa Berlian Motor cabang Bone". Makassar.

Sugiyono. 2014. Metode Penelitian Kuantitatif, Kualitatif, dan $R \& D$.

Bandung : Alfabeta.

Tjiptono, Fandy. 2008. Strategi Pemasaran Edisi III. Yogyakarta : $\quad$ Andi Offset.

Wiyono, Gendro. 2011. Merancang Penelitian Bisnis dengan Alat Analisis SPSS 17.0 \& Smart PLS 2.0. Unit Penerbit dan Percetakan STIM YKPN. Yogyakarta.

Yohanes. 2017. "Pengaruh Persepsi Harga, Kualitas Produk, dan Citra Merek Terhadap Keputusan Pembelian Sepeda Motor Honda Matic (Studi Kasus Pada Mahasiswa Kampus I Universitas Sanata Dharma Yogyakarta)". Universi- tas Sanata Dharma.Yogyakarta.

http://www.astra-honda.com (di akses 25/11/2018 pukul 08:00)

http://www.aisi.or.id (Di akses tanggal 25/11/2018 jam 14:00) 